\title{
VISUAL OUTCOME AFTER LASER IN SITU KERATOMILEUSIS (LASIK) IN PATIENTS OF MYOPIA
}

\author{
Syed Heena Kubravi', Syed Tariq Qureshi², Shah Nawaz ${ }^{3}$, Arshi Nazir 4 , Tania Sadiq ${ }^{5}$ \\ ${ }_{1}^{1}$ Postgraduate, Department of Ophthalmology, GMC, Srinagar. \\ 2 Professor and HOD, Department of Ophthalmology, GMC, Srinagar. \\ ${ }^{3}$ Lecturer, Department of Ophthalmology, GMC, Srinagar. \\ ${ }^{4}$ Senior Resident, Department of Ophthalmology, GMC, Srinagar. \\ ${ }^{5}$ Postgraduate, Department of Ophthalmology, GMC, Srinagar.
}

\begin{abstract}
BACKGROUND

A hospital-based study to evaluate the visual outcome after LASIK in patients of myopia.

\section{MATERIALS AND METHODS}

A total of 103 patients (200 eyes) with myopia and myopic astigmatism between -1.00 and -8.25 diopters (D) and up to $-2.75 \mathrm{D}$ astigmatism underwent LASIK treatment using the Carl Zeiss Meditec AG's MEL 80 (Germany) laser. The preoperative examination included assessment of UCVA and BCVA, slit lamp biomicroscopy, specular microscopy, non-contact tonometry, fundus evaluation, autokeratometry, corneal topography and corneal pachymetry. Patients were examined at 1 week, 1 month and 3 months following surgery. Parameters evaluated at each followup visit were Uncorrected Visual Acuity (UCVA), Best Spectacle Corrected Visual Acuity (BSCVA), residual refractive error and presence of any complications.
\end{abstract}

\section{RESULTS}

The mean preoperative UCVA (logMAR) improved from $1.203 \pm 0.289$ to a value of $0.047 \pm 0.085$ and $0.037 \pm 0.077$ at the end of 1 month and 3 months postoperatively. A postoperative UCVA of $6 / 6$ was achieved in $81 \%$ eyes, $6 / 9$ in $17 \%$ eyes and $6 / 12$ in $2 \%$ eyes at the end of 3 months when measured with the Snellen's visual acuity chart. The mean BCVA (logMAR) improved from $0.029 \pm 0.066$ to $0.025 \pm 0.063$ and $0.023 \pm 0.060$ at the end of 1 month and 3 months postoperatively; $87 \%$ eyes achieved a postoperative BCVA of $6 / 6$, while $13 \%$ achieved a BCVA of $6 / 9$. At the end of 3 months, the mean spherical equivalent of refraction was $-0.24 \pm 0.369$ compared to a preoperative mean of $-4.81 \pm 2.053$. A gain of one line of BCVA was seen in 5 eyes; 193 eyes retained their preoperative BCVA, while a loss of one line of BCVA was seen in 2 eyes. Postoperatively, dry eyes were found to be the most common problem followed by glare, striae and astigmatism.

\section{CONCLUSION}

For the correction of low-to-moderate myopia with lower degrees of astigmatism results from our study have shown that LASIK is effective and predictable in terms of obtaining very good-to-excellent uncorrected visual acuity.

\section{KEYWORDS}

Laser In-Situ Keratomileusis (LASIK), Myopia, Uncorrected Visual Acuity (UCVA).

HOW TO CITE THIS ARTICLE: Kubravi SH, Qureshi ST, Nawaz S, et al. Visual outcome after laser in situ keratomileusis (LASIK) in patients of myopia. J. Evolution Med. Dent. Sci. 2016;5(94):6932-6935, DOI: 10.14260/Jemds/2016/1569

\begin{abstract}
BACKGROUND
Myopia is a common human ocular disorder. With its increasing prevalence and earlier age of onset in recent birth cohorts, myopia now affects almost 33\% adults in US and epidemic proportions from $85 \%$ to $90 \%$ adults in Asian cities. 1 Single vision spectacle lenses and contact lenses are commonly prescribed for myopia and more recently refractive surgery has become a popular option. ${ }^{2}$ In the history of refractive surgery, an important development has occurred in the use of excimer systems offering the possibility to change the anterior corneal refractive power through a controlled stromal ablation. ${ }^{3}$
\end{abstract}

Financial or Other, Competing Interest: None.

Submission 05-10-2016, Peer Review 12-11-2016,

Acceptance 18-11-2016, Published 24-11-2016.

Corresponding Author:

Syed Heena Kubravi,

H. No. 178, Botashah Colony,

Lal Bazar, Srinagar-190023.

Jammu and Kashmir, India.

E-mail: syedheenak@gmail.com

DOI: $10.14260 /$ jemds $/ 2016 / 1569$
Laser in-situ keratomileusis (LASIK) combines the precision of excimer laser photoablation with the advantages of an intrastromal procedure that maintains the integrity of Bowman's layer and the overlying corneal epithelium. The procedure is performed by the Excimer Laser by removing the tissues with liberation of sufficient energy with a specific wavelength $(193 \mathrm{~nm})$ to interrupt the tissue's intermolecular bundles in a short time in order to avoid any harm to the surrounding tissues. 4

The purpose of this study was to evaluate the safety and effectiveness of laser in situ keratomileusis (LASIK) performed with a scanning excimer laser to correct myopia and low-tomoderate levels of astigmatism.

\section{MATERIALS AND METHODS}

This study was conducted at the LASIK Centre in the Postgraduate Department of Ophthalmology, Government Medical College, Srinagar, for a period of one and a half years (from April 2014 to October 2015). 


\section{Inclusion Criteria}

Patients were enrolled if they met the following criteria: Age > 18 years, preoperative cycloplegic spherical refraction between $-1.00 \mathrm{D}$ and $-8.25 \mathrm{D}$ of myopia and up to $-2.75 \mathrm{D}$ of myopic astigmatism, a stable refraction (change $<0.5 \mathrm{D}$ per year) for at least 1 year, preoperative BCVA $\geq 6 / 9$, sufficient corneal thickness for full correction with residual stromal thickness of at least 250 micron remaining beneath LASIK flap. Informed written consent was obtained from all the patients in local language.

\section{Exclusion Criteria}

Patients were excluded from the study if they had a history of any ocular disease, keratoconus or forme fruste keratoconus, connective tissue disorder, pregnancy or severe dry eye syndrome.

\section{Preoperative Assessment}

A proper history regarding the type of treatment used previously was taken. Patients using contact lenses were instructed to remove (soft contact lenses 2 weeks and rigid contact lenses 4 weeks) before their preoperative examination as well as before surgery. The preoperative examination included: Assessment of UCVA and BCVA, slit lamp biomicroscopy, specular microscopy, non-contact tonometry, fundus evaluation, autokeratometry, corneal topography and corneal pachymetry.

\section{LASER}

The laser used was Carl Zeiss Meditec AG's MEL 80 (Germany). It is a spot scanning laser with a Gaussian laser beam and is equipped with a CCA+ System (cone for controlled atmosphere) and an active eye tracker. It is operated via the OPASS software (operation assistant) running on a windows based PC. Using this software, the surgeon is able to enter clinical data and to monitor treatment progress on a display.

\section{Microkeratome}

The microkeratome used was the Moria One Use-Plus microkeratome (France). It is an automated, mechanical, linear microkeratome designed to create nasal hinged flaps in corneas with keratometry between 39 and 49D.

\section{Preoperative Data}

A total of 103 patients (200 eyes) with myopia were included, which fell in the age group of 19 to 36 years; 97 patients underwent LASIK in both eyes, while only one eye was operated in 6 patients. In our series, 58.2\% (60 patients) were males and $41.7 \%$ (43 patients) were females; $79.6 \%$ (82) patients used spectacles, while $20.3 \%$ (21) depended on contact lens for myopic correction before LASIK. The flat $\mathrm{K}$ (K1) values ranged from $40.71 \mathrm{D}$ to $47.48 \mathrm{D}$ with a mean value of $43.97 \mathrm{D} \pm 1.54 \mathrm{SD}$. The steep $\mathrm{K}(\mathrm{K} 2)$ values ranged from $40.75 \mathrm{D}$ to $48.48 \mathrm{D}$ with a mean value of $44.04 \mathrm{D} \pm 1.62 \mathrm{SD}$. The central corneal thickness ranged from 442 to 590 microns with a mean of 515.7 microns \pm 36.43 and endothelial cell count ranged from 2365 to 3578 cells per $\mathrm{mm}^{2}$ with a mean of 2874.6 cells per $\mathrm{mm}^{2} \pm 225.14$. The Uncorrected Visual Acuity (UCVA) measured in patients undergoing LASIK ranged from $1 / 60$ to $6 / 36$. The mean preoperative spherical refraction was of $-4.58 \pm 2.03 \mathrm{D}$ and mean cylinder was $-0.46 \mathrm{D} \pm 0.656 \mathrm{D}$. The mean spherical equivalent of refraction was $-4.81 \mathrm{D} \pm 2.053 \mathrm{D}$ (range - $0.875 \mathrm{D}$ to -9D). Preoperatively, a best corrected visual acuity of $6 / 6$ was found in $84 \%$ eyes, while $16 \%$ eyes had a best spectacle visual acuity of $6 / 9$.

\section{Surgical Technique}

A standard surgical treatment $5,6,7,8$ protocol was used: room temperature $21 * \mathrm{C} \pm 1 * \mathrm{C}(70 * \pm 2 * \mathrm{~F})$, humidity $45 \% \pm 5 \%$.

In the laser room prior to keratectomy a topical anaesthetic, proparacaine $0.5 \%$ (Alcaine - Alcon, Belgium) was instilled in the eye. Povidone iodine 5\% antisepsis was applied on the eyelids and eyelid margins.

After obtaining proper exposure with an eye speculum, the cornea was marked with gentian violet to ensure proper centration of suction ring and proper realignment of the flap. A 9 to $9.5 \mathrm{~mm}$ diameter, nasal hinged anterior corneal flap was created using the automated One Use-Plus microkeratome. This was followed by excimer ablation, centered on the pupil with optical zones of $6 \mathrm{~mm}$.

At the end of the laser treatment, the interface was irrigated with 1 to $2 \mathrm{cc}$ of balanced salt solution and the flap was repositioned. After a 15 seconds waiting period, a drop of moxifloxacin hydrochloride $0.5 \%$ was applied and the speculum was removed.

\section{Postoperative Treatment Protocol}

Post-operative treatment consisted of moxifloxacin 0.5\%, dexamethasone $0.1 \%$ drops (Milflox DM - Sun Pharmaceuticals, India) - four times daily for 1 week; and artificial tears (Tears Naturale II - Alcon Belgium) every hour at day 1 and 2, and four to six times a day thereafter for a duration of 2 to 10 weeks.

\section{Followup Examination}

Patients were examined at 1 week, 1 month and 3 months following surgery.

\section{Outcome Measures}

Parameters evaluated at each followup visit were Uncorrected Visual Acuity (UCVA), Best Corrected Visual Acuity (BCVA), residual refractive error and presence of any complications. At each followup, patients were questioned about eventual side effects.

\section{Statistical Analysis \\ SPSS (version 20.0) and Microsoft Excel were used to carry out the statistical analysis of data. Continuous variables were summarised as mean and standard deviation and categorical variables as percentage. Data was presented by bar diagrams and pie charts. Paired ' $t$ ' test was used for comparison of pre- and post-LASIK visual acuity and refraction. $P$ value less than 0.05 was considered statistically significant.}

\section{RESULTS \\ Visual Outcome}

The mean preoperative UCVA (logMAR) improved from 1.203 \pm 0.289 to a value of $0.047 \pm 0.085$ and $0.037 \pm 0.077$ at the end of 1 month and 3 months (final visit) postoperatively. (Baseline Vs 1 month: P value < 0.001; Baseline Vs 3 months: $\mathrm{P}$ value $<0.001)$. When measured with the Snellen's visual acuity chart a postoperative UCVA of $6 / 6$ was achieved in $81 \%$ eyes, $6 / 9$ in $17 \%$ eyes and $6 / 12$ in $2 \%$ eyes at the end of final visit. 
The mean BCVA (logMAR) improved from $0.029 \pm 0.066$ to $0.025 \pm 0.063$ and $0.023 \pm 0.060$ at the end of 1 month and 3 months postoperatively. When measured with the Snellen's visual acuity chart $87 \%$ eyes achieved a BCVA of $6 / 6$, while $13 \%$ achieved a BCVA of $6 / 9$ following LASIK at the end of final visit.

\section{Post LASIK UCVA in Studied Eyes}

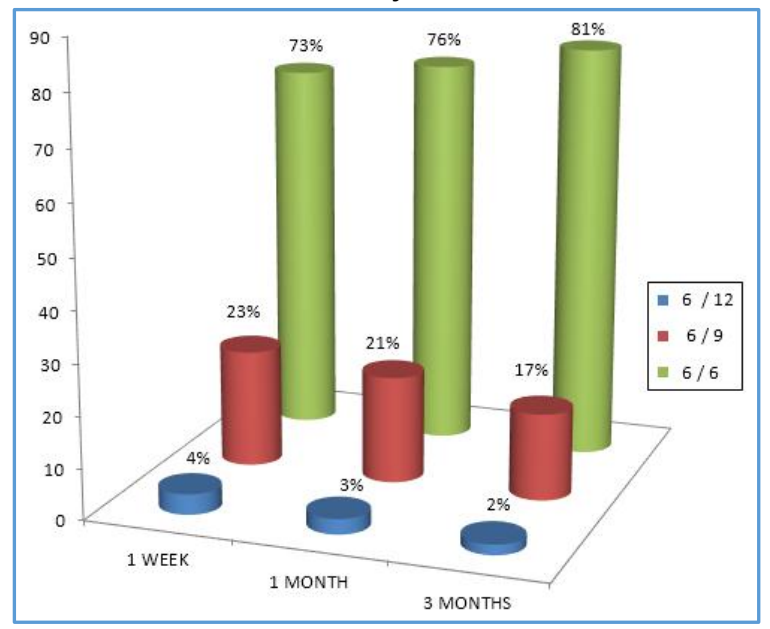

\section{Refractive Outcome}

The mean preoperative spherical equivalent of refraction was $-4.81 \pm 2.053 \mathrm{D}$, which reduced significantly to a mean value of $-0.25 \pm 0.329 \mathrm{D}$ and $-0.24 \pm 0.369 \mathrm{D}$ ( $\mathrm{p}$ value $<0.001$ ) at the end of 1 month and 3 months respectively. The mean sphere changed from $-4.58 \pm 2.026 \mathrm{D}$ to $-0.17 \pm 0.268 \mathrm{D}$, while the mean cylinder changed from $-0.46 \pm 0.656 \mathrm{D}$ to $-0.13 \pm$ $0.265 \mathrm{D}$, the improvement being statistically significant ( $p$ value $<0.001$ ) in both cases.

\begin{tabular}{|c|c|c|c|c|c|c|}
\hline \multirow{2}{*}{\multicolumn{2}{|c|}{ Refraction Parameters }} & \multirow{3}{*}{$\begin{array}{c}\text { Mean } \\
-4.58\end{array}$} & \multirow{3}{*}{$\begin{array}{c}\text { SD } \\
2.026\end{array}$} & \multicolumn{3}{|c|}{ Multiple Comparisons } \\
\hline & & & & \multirow{2}{*}{$\begin{array}{c}\text { Comparison } \\
1 \text { vs } 2\end{array}$} & \multirow{2}{*}{$\begin{array}{c}\text { T-value } \\
22.89\end{array}$} & \multirow{2}{*}{$\frac{\text { P-value@ }^{@}}{<0.001^{*}}$} \\
\hline \multirow{4}{*}{ Sphere } & Baseline (1) & & & & & \\
\hline & 1 Week (2) & -0.23 & 0.305 & 1 vs 3 & 22.73 & $<0.001^{*}$ \\
\hline & 1 Month (3) & -0.18 & 0.264 & 1 vs 4 & 22.68 & $<0.001^{*}$ \\
\hline & 3 Months (4) & -0.17 & 0.268 & 3 vs 4 & 0.491 & $0.625^{\#}$ \\
\hline \multirow{4}{*}{ Cylinder } & Baseline (1) & -0.46 & 0.656 & 1 vs 2 & 4.52 & $<0.001^{*}$ \\
\hline & 1 Week (2) & -0.17 & 0.352 & 1 vs 3 & 4.97 & $<0.001^{*}$ \\
\hline & 1 Month (3) & -0.15 & 0.271 & 1 vs 4 & 5.23 & $<0.001^{*}$ \\
\hline & 3 Months (4) & -0.13 & 0.265 & 3 vs 4 & 1.28 & $0.202^{\#}$ \\
\hline \multirow{4}{*}{ MSE } & Baseline (1) & -4.81 & 2.053 & 1 vs 2 & 24.41 & $<0.001^{*}$ \\
\hline & 1 Week (2) & -0.31 & 0.400 & 1 vs 3 & 24.63 & $<0.001^{*}$ \\
\hline & 1 Month (3) & -0.25 & 0.329 & 1 vs 4 & 25.95 & $<0.001^{*}$ \\
\hline & 3 Months (4) & -0.24 & 0.369 & 3 vs 4 & 0.81 & $0.420^{\#}$ \\
\hline
\end{tabular}

*Statistically Significant Difference $(\mathrm{P}-$ value $<0.05)$; \#Statistically Non-Significant Difference ( $\mathrm{P}$ - value $>0.05$ )

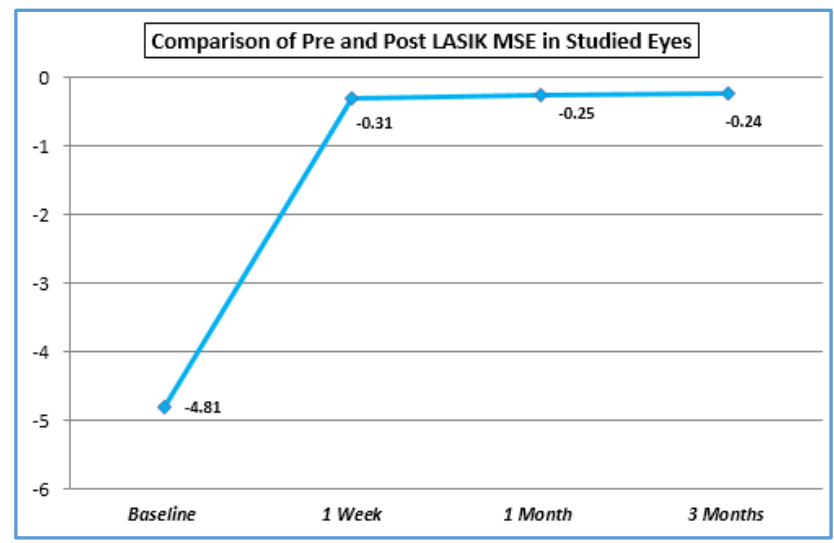

\section{Line Improvement}

At the end of 1 Week, 3 eyes showed a loss of 1 line in Best Corrected Visual Acuity (BCVA). Visual acuity improved in 1 eye during the subsequent followup period and at the end of 1
Month and 3 Months; only 2 eyes showed loss of 1 line in Best Corrected Visual Acuity. BCVA remained unchanged in 193 eyes at the end of 3 Months. Gain in 1 line of Best Corrected Visual Acuity was seen in 1 eye at the end of 1 Week and in 4 and 5 eyes at the end of 1 Month and 3 Months respectively.

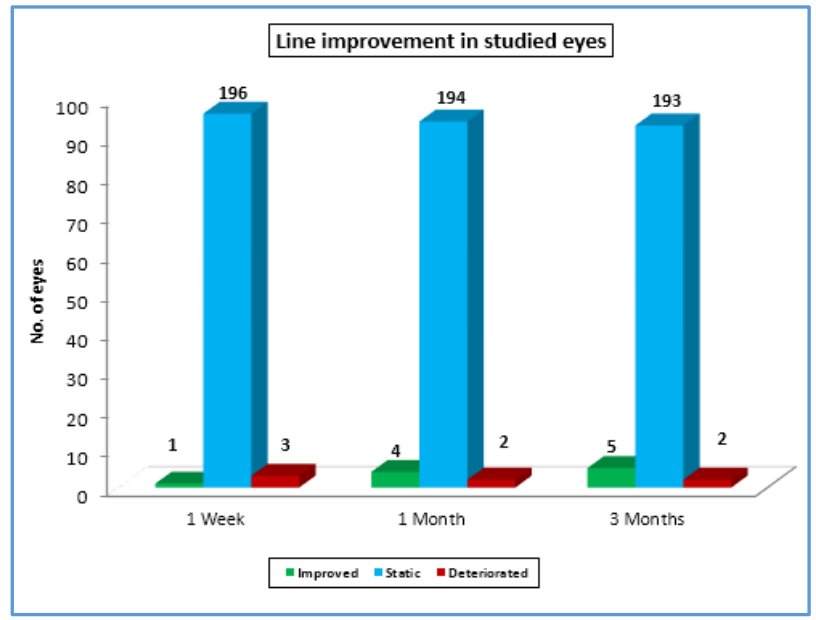




\section{COMPLICATIONS}

\begin{tabular}{|c|c|c|}
\hline Complications & No. of Patients & (\% Age) \\
\hline Dry eyes & 20 & 19.41 \\
\hline Glare & 6 & 5.82 \\
\hline Microstriae & 8 & 7.76 \\
\hline Macrostriae & 2 & 1.94 \\
\hline Astigmatism & 8 & 7.76 \\
\hline Nil & 59 & 57.28 \\
\hline \multicolumn{2}{|c|}{ Table 2. Complications Following LASIK } \\
\hline
\end{tabular}

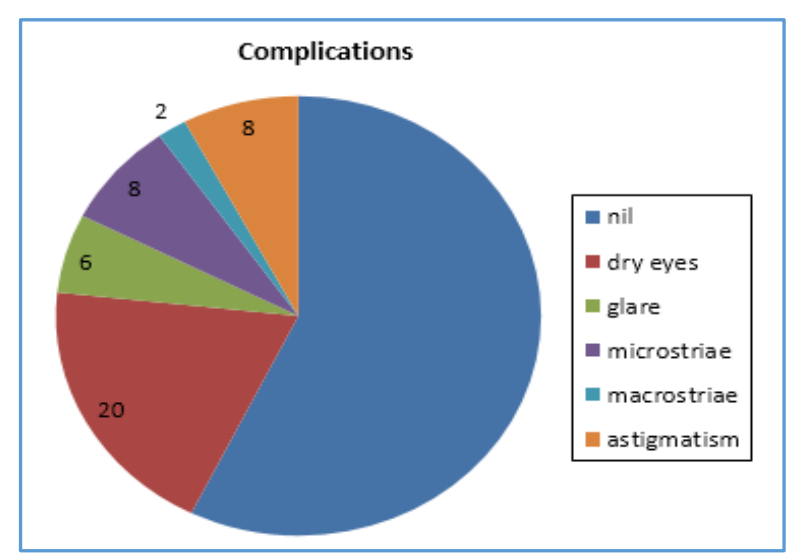

\section{DISCUSSION}

This study addressed the treatment of myopia and astigmatism using Carl Zeiss Meditec AG's MEL 80 spot scanning laser. Out of the 200 eyes studied with a preoperative BCVA of 6/9 (logMAR 0.18) or better, an uncorrected visual acuity of $6 / 6$ (logMAR 0 ) was achieved in $81 \%$ eyes, a visual acuity of $6 / 9$ or better was achieved in $98 \%$ eyes and $6 / 12$ or better in $100 \%$ eyes at the end of 3 months. Shaheen et al (2013) ${ }^{9}$ reported a postoperative logMAR UCVA 0.1 or better in $98 \%$ eyes at the end of 1 year, which supports our results.

Preoperative mean spherical equivalent refraction of -4.81 $\pm 2.053 \mathrm{D}$ was reduced to $-0.25 \pm 0.329 \mathrm{D}$ at 1 month and -0.24 $\pm 0.369 \mathrm{D}$ at 3 months, the difference between the two followups being non-significant ( $p$ value $<0.198$ ). This suggests that the refraction remains stable during the followup period.

A change of 2 or more lines has been generally indicated as the standard of safety. ${ }^{10}$ In our study no eye lost 2 or more lines of BCVA postoperatively, thus indicating that LASIK is a safe procedure, especially when all the preoperative parameters are taken care of and a standard surgical protocol is followed. In our study 5 eyes gained 1 line, while 193 eyes retained their best corrected visual acuity at the end of 3 months postoperatively. The efficacy index for the procedure (mean postoperative UCVA/mean preoperative BCVA) was 1.27. Goes FJ et al $(2005)^{6}$ reported an efficacy index of 1.11 , while Schallhorn et al (2009) ${ }^{4}$ reported an efficacy index of 0.96. It is possible that patients who had a gain in BCVA postoperatively may have been mild-to-moderate myopes during the critical period of visual development and amblyopia may not have occurred. With increasing age the myopia and astigmatism increased and the patients began to wear stronger spectacles resulting in reduced visual function from image minification. Following LASIK, object minification was significantly decreased resulting in the reported improvement in UCVA and BCVA. ${ }^{11}$

The most common side effect of LASIK observed in the 3month followup period was dry eyes. This is because of neurotrophic epitheliopathy as a result of the severing of corneal nerves with the keratome blade, decrease in conjunctival and corneal sensitivity and a change in the tear lipid layer. ${ }^{12}$

Other complications include microstriae, macrostriae and astigmatism. Errors may have occurred following rotational ocular shift or drift during laser ablation. Other factors such as cyclotorsion between the sitting and supine position and the lamellar cut may also have contributed to astigmatism alteration.

Myopic regression usually is seen in patients of high myopia. Significant postoperative myopic shift was not seen in any patient during the 3-month followup, but possibility of regression occurring in later postoperative period cannot be ruled out.

The major limitation of this study was the short period of followup of 3 months. Visual improvement can occur for several months after LASIK. Visual results may improve in the later postoperative period. Also, while most complications after laser occur during the perioperative period, some complications can occur much later; ectasia has been reported to occur several years after the surgery. Myopic regression may also be observed in long-term followup.

To conclude, results of LASIK were encouraging in our study and the overall visual outcome was satisfactory for majority of the patients.

\section{REFERENCES}

1. Lei Yu, Zhi-Kui Li, Jin-Rong Gao, et al. Epidemiology, genetics and treatments for myopia. Int J Ophthalmol 2011;4(6):658-69.

2. Gwiazda J. Treatment options for myopia. Optom Vis Sci 2009;86(6):624-8.

3. Fernandez MR, Tackman RN. Healing changes and secondary findings with confocal microscopy. LASIKLASEK: New horizons in quality of vision. $1{ }^{\text {st }}$ edn. Panama: international communications 2003:51-7.

4. Reyes AR, Sanchez-Galeana CA. Laser tissue effect. LASIKLASEK:New horizons in quality of vision. $1^{\text {st }}$ edn. Panama: international communications 2003:43-50.

5. Montes M, Chayet A, Gomez L, et al. Laser in situ keratomileusis for myopia of -1.50 to -6.00 diopters. J Refract Surg 1999;15(2):106-10.

6. Goes FJ. LASIK for myopia with the Zeiss meditec MEL 80 J Refract Surg 2005;21(6):691-7.

7. Schallhorn SC, Venter JA. One-month outcomes of wavefront-guided LASIK for low to moderate myopia with the VISX STAR S4 laser in 32,569 eyes. J Refract Surg 2009;25(7 Suppl):S634-41.

8. Padmanabhan P, Basuthkar SS, Joseph R. Ocular aberrations after wavefront optimized LASIK for myopia. Indian Journal of Ophthalmol 2010;58(4):307-12.

9. Shaheen MS, Massoud TH, Ezzeldin H, et al. Four-year visual, refractive, and contrast sensitivity outcomes after wavefront-guided myopic LASIK using an advanced excimer laser platform. J Refract Surg 2013;29(12):81622.

10. Waring GO. Standard graphs for reporting refractive surgery. J Refract Surg 2000;16(4):459-66.

11. Rui he, Qu M, Fen Y, et al. Improvement of best spectaclecorrected visual acuity after LASIK in highly myopic eyes with reduced preoperative best spectacle-corrected visual acuity. J Refract Surg 2006;22 (9 Suppl):S1053-5.

12. Iqbal MS, Jafri AS, Mahar PS. Outcome of laser in situ keratomeliusis (lasik) in low to high myopia: review of 200 cases. Pak J Ophthalmol 2008;24(3):127-31. 